\section{Reply to Pelosi}

J.-M. Dumonceau, A. Riphaus,

J. R. Aparicio, U. Beilenhoff,

M. Ortmann, G. Paspatis, C. Y. Ponsioen,

I. Racz, F. Schreiber, P. Vilmann,

T. Wehrmann, B. Walder, H. Neuhaus, and

NAAP Task Force members

The European Society of Anaesthesiology (ESA) has retracted its endorsement of the Guideline: Non-anaesthesiologist administration of propofol for GI endoscopy more than one year after giving that approval $[1-3]$. The Guideline was produced by a committee that included members of the ESA, of the European Society of Gastrointestinal Endoscopy (ESGE), and of the European Society of Gastroenterology and Endoscopy Nurses and Associates (ESGENA) [2,3]. This committee had worked together in an attempt to improve the quality and safety of care for the patient undergoing GI interventions. The German S3 Guideline on sedation in GI endoscopy is another example of this interdisciplinary process at a national level [4].

The subject of non-anesthesiologist administration of propofol is not new: the European Board of Anaesthesiology (EBA) had already made recommendations in 2007 about the use of propofol in its Guidelines for sedation and/or analgesia by non-anaesthesiology doctors [5]. The ESGE-ESGENA-ESA Guideline is completely in line with the recommendations made in that EBA Guideline. And, as noted in the ESA retraction of their endorsement [1], "Following evaluation of the scientific evidence by the ESA guidelines committee, the Board of Directors of the ESA decided unanimously to endorse the report." We are astonished that the ESA endorsement of the Guideline was withdrawn for political reasons and not on the basis on new evidence that contradicted the Guideline [6]. We understand that there are two strands of opinion in the ESA, one supporting and the other opposing the Guideline [6]. Endorsement of a guideline should be retracted if new evidence appears that contradicts the Guideline. As the ESA has so far failed to support its statement with evidence-based arguments, we feel that the retraction of its endorsement of the Guideline for the nonanesthesiologist administration of propofol for GI endoscopy is not in line with current standards of international guideline development. Because of the given evidence for the Guideline recommendations and its scientific value, ESGE and ESGENA continue to endorse the Guideline.

This letter is being published simultaneously in Endoscopy and the European Journal of Anaesthesiology.

\section{Competing interests: None}

\section{References}

1 Pelosi P. Retraction of endorsement: European Society of Gastrointestinal Endoscopy, European Society of Gastroenterology and Endoscopy Nurses and Associates, and the European Society of Anaesthesiology Guideline: Non-anaesthesiologist administration of propofol for GI endoscopy. Endoscopy 2012; 44: 2-14

2 Dumonceau JM, Riphaus A, Aparicio JR et al. European Society of Gastrointestinal Endoscopy, European Society of Gastroenterology and Endoscopy Nurses and Associates, and the European Society of Anaesthesiology Guideline: Non-anaesthesiologist administration of propofol for GI endoscopy. Eur J Anaesth 2010; 27: 1016-1030

3 Dumonceau JM, Riphaus A, Aparicio JR et al. European Society of Gastrointestinal Endoscopy, European Society of Gastroenterology and Endoscopy Nurses and Associates, and the European Society of Anaesthesiology Guideline: Non-anesthesiologist administration of propofol for GI endoscopy. Endoscopy 2010; 42: 960-974

4 Riphaus A, Wehrmann T, Weber B et al. S3 Guideline: Sedation for gastrointestinal endoscopy 2008. Endoscopy 2009; 41: $787-$ 815

5 Knape JTA, Adriaensen $H$, van Aken $H$ et al. Guidelines for sedation and/or analgesia by non-anaesthesiology doctors. Section and Board of Anaesthesiology, European Union of Medical Specialists. Eur J Anaesthesiol 2007; 24: 563-567

6 Werner C, Smith A, Van Aken H. Guidelines on non-anaesthesiologist administration of propofol for gastrointestinal endoscopy: a double-edged sword. Eur J Anaesthesiol 2011; 28: 553-555

J.-M. Dumonceau, MD PhD

Division of Gastroenterology and

Hepatology

Geneva University Hospitals

Rue Micheli-du-Crest 24

1205 Geneva

Switzerland

Fax: +41-22-3729366

jmdumonceau@hotmail.com
A. Riphaus, MD PhD
Ruhr University Bochum
Department of Medicine
Knappschaftskrankenhaus
In der Schornau 23-25
44892 Bochum
Germany
Fax: +49-234/299-3439
ariphaus@web.de

\footnotetext{
* NAAP (Non-Anesthesiologist Administration of Propofol) Task Force: Lars Aabakken, Anthony Axon, Guido Costamagna, Emiliano Giostra, Pernille Hornslet, Spiros Ladas, Tomasz Marek, Mario Dinis-Ribeiro
} 